Supporting Information

\title{
Numerical Modeling for Sensitive and Rapid Molecular Detection by Membrane-Based Immunosensors
}

Hiroto Okuyama, Takanori Tamaki, Yuhei Oshiba, Hiroshi Ueda, Takeo Yamaguchi* Laboratory for Chemistry and Life Science, Tokyo Institute of Technology, 4259 Nagatsutacho, Midori-ku, Yokohama, Kanagawa, 226-8503, Japan

*Corresponding author. Email: yamag@res.titech.ac.jp

\section{Table of Contents:}

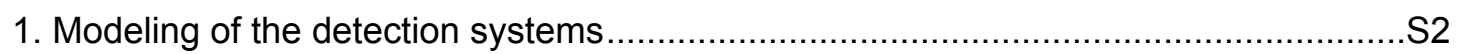

1-1. Modeling of the membrane-based immunosensor ............................................. 22

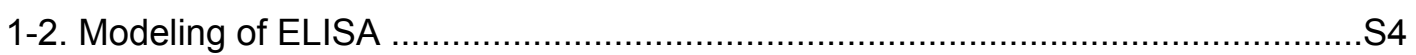

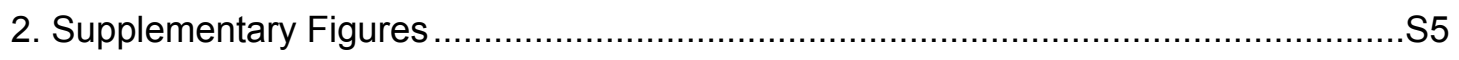

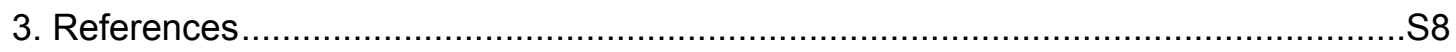




\section{Modeling of the detection systems}

\section{1-1. Modeling of the membrane-based immunosensor}

To simplify the membrane-based sensing model, the time constant $\left(\tau_{1}\right)$ for flow into the membrane pore $(0.5 \mu \mathrm{m}$ radius and $22 \mu \mathrm{m}$ length) is compared with that for radial diffusion in the pore $\left(\tau_{2}\right)$. Here, $\tau_{1}$ and $\tau_{2}$ are calculated as follows:

$\tau_{1}=\frac{l}{\vec{u}}=\frac{22 \times 10^{-6}[\mathrm{~m}]}{5.5 \times 10^{-5}[\mathrm{~m} / \mathrm{s}]}=0.41$

$\tau_{2}=\frac{r^{2}}{D_{\mathrm{Ab}}}=\frac{\left(0.5 \times 10^{-6}[\mathrm{~m}]\right)^{2}}{4 \times 10^{-11}}=6.25 \times 10^{-3}$

The numerical calculation in each step is carried out according to the following equations.

\section{$\underline{1^{\text {st }} \text { step }}$}

$\mathrm{Ag}$ is associated with the $A b_{1}$ in this step. Dissociation of captured $A b_{1}-A g$ also occurs.

Therefore, this step is described as follows:

1. Association of $\mathrm{Ag}$

$\frac{\partial C_{\mathrm{Ag}}}{\partial t}=-\vec{u} \frac{\partial C_{\mathrm{Ag}}}{\partial x}-k_{\mathrm{on}} C_{\mathrm{Ag}} C_{\mathrm{Ab} 1}+k_{\mathrm{off}} C_{\mathrm{Ab} 1-\mathrm{Ag}}$

2. Dissociation of $\mathrm{Ag}$

$\frac{\partial C_{\mathrm{Ab} 1-\mathrm{Ag}}}{\partial t}=k_{\mathrm{on}} C_{\mathrm{Ag}} C_{\mathrm{Ab} 1}-k_{\mathrm{off}} C_{\mathrm{Ab} 1-\mathrm{Ag}}$

Here, $A b_{1}-A g$ is $A g$ captured in the pore. Other parameters are the same as in Table 1.

\section{$\underline{2}^{\text {nd }}$ step}

The association and dissociation between $A b_{2}$ and $A b_{1}-A g$ are considered in this step.

1. Association of $A b_{2}$

$\frac{\partial C_{\mathrm{Ab} 2}}{\partial t}=-\vec{u} \frac{\partial C_{\mathrm{Ab} 2}}{\partial x}-k_{\mathrm{on}} C_{\mathrm{Ab} 1-\mathrm{Ag}} C_{\mathrm{Ab} 2}+k_{\mathrm{off}} C_{\mathrm{Ab} 1-\mathrm{Ag}-\mathrm{Ab} 2}$ 
2. Dissociation of $A b_{2}$

$\frac{\partial C_{\mathrm{Ab} 1}-\mathrm{Ag}-\mathrm{Ab} 2}{\partial t}=k_{\mathrm{on}} C_{\mathrm{Ab} 1-\mathrm{Ag}} C_{\mathrm{Ab} 2}-k_{\mathrm{off}} C_{\mathrm{Ab} 1-\mathrm{Ag}-\mathrm{Ab} 2}$

In this step, the dissociation and reassociation of $\mathrm{Ag}$ that are recognized in the $1^{\text {st }}$ step are also considered, as follows:

3. Dissociation of $\mathrm{Ag}$

$\frac{\partial \mathrm{C}_{\mathrm{Ab} 1-\mathrm{Ag}}}{\partial t}=k_{\mathrm{on}} C_{\mathrm{Ag}} C_{\mathrm{Ab} 1}-k_{\mathrm{off}} C_{\mathrm{Ab} 1-\mathrm{Ag}}$

4. Reassociation of $\mathrm{Ag}$

$\frac{\partial C_{\mathrm{Ag}}}{\partial t}=-\vec{u} \frac{\partial C_{\mathrm{Ag}}}{\partial x}-k_{\text {on }} C_{\mathrm{Ag}} C_{\mathrm{Ab} 1}-k_{\mathrm{off}} C_{\mathrm{Ab} 1-\mathrm{Ag}}$

\section{$\underline{3}^{\text {rd }}$ step}

The substrate for the enzyme in the $A b_{2}$ (HRP) is oxidized. This reaction is described with the Michaelis-Menten equation. Thus,

$\frac{\partial C_{\mathrm{sub}(\mathrm{ox})}}{\partial t}=-\vec{u} \frac{\partial C_{\mathrm{sub}(\mathrm{ox})}}{\partial x}-\frac{k_{\mathrm{cat}} \cdot C_{\mathrm{enz}}}{C_{\mathrm{sub}}+K_{\mathrm{m}}} C_{\mathrm{sub}}$

Here, $C_{\text {sub }}$ and $C_{\text {sub(ox) }}$ is the concentration of the substrate (TMB) and the oxidized substrate, respectively, and $C_{\text {enz }}$ is the concentration of the enzyme, which is calculated as $4 \times C_{\mathrm{Ab} 1-\mathrm{Ag} \text { - }}$ $A b 2$, because $A b_{2}$ has 4 enzymes per 1 molecule in this study.

For the calculation without flow, the region for molecular diffusion is assumed in front of the pore (see Figure S2(a)). In this model, the flow rate $(u)$ is set to 0 in the above equations. In addition, the following equation is used.

$\frac{\partial C}{\partial t}=D \frac{\partial^{2} C}{\partial x^{2}}$

Here, $C$ is the concentration of the diffused molecules, and $D$ is the diffusion coefficient of the molecule. 


\section{1-2. Modeling of ELISA}

The density of the sandwich structure formation in the solid-liquid interface is simulated using COMSOL Multiphysics. In this modeling, the well plate is assumed to be $6 \mathrm{~mm}$ in diameter and $3.5 \mathrm{~mm}$ in height, which are the same conditions as when a typical 96-well plate is filled with $100 \mu \mathrm{L}$ of analytes. The density of the adsorbed $A b_{1}$ on the bottom and sides of the wells was assumed to be $300 \mathrm{ng} / \mathrm{cm}^{2}$, which is the maximum amount of antibody adsorbed on a standard polystyrene plate, and $5 \%$ of adsorbed $A b_{1}$ were assumed to remain activated ${ }^{1}$.

The calculated enzyme concentration at the interface $(4 \times$ the concentration of the sandwich formation) is used to solve the following equation.

$\underline{\text { Interface }} \frac{\partial C_{\text {sub(ox) }}}{\partial t}=D_{\text {sub(ox) }} \frac{\partial^{2} C_{\text {sub(ox) }}}{\partial x^{2}}+\frac{k_{\text {cat }} \cdot C_{\text {enz }}}{C_{\text {sub }}+K_{\mathrm{m}}} C_{\text {sub }}$

$\underline{\text { Non-interface }}$

$\frac{\partial C_{\mathrm{sub}(\mathrm{ox})}}{\partial t}=D_{\mathrm{sub}(\mathrm{ox})} \frac{\partial^{2} C_{\mathrm{sub}(\mathrm{ox})}}{\partial x^{2}}$

Here, $D_{\text {sub(ox) }}$ is the diffusion coefficient of the oxidized substrate and is assumed to be the same as $D_{\mathrm{TMB}}$.

The absorbance is calculated by using Lambert-Beer's law, as follows.

$A=\epsilon c L$

Here, $A$ is the absorbance, $\varepsilon$ is the molar attenuation coefficient, and $L$ is the optical path length.

\section{Supplementary figures}




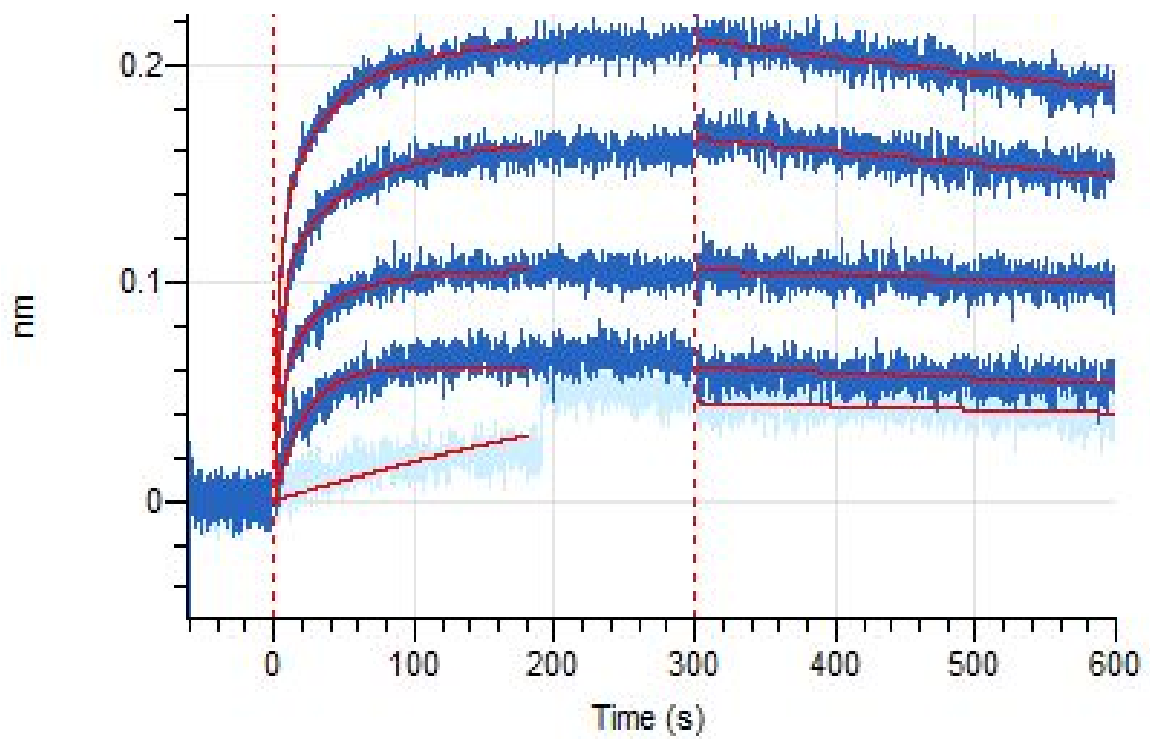

\begin{tabular}{|c|c|c|c|c|c|c|c|}
\hline$C_{\mathrm{ab}}(\mathrm{nM})$ & Response & $K_{\mathrm{D}}(\mathrm{M})$ & $K_{\mathrm{D}}$ Error & $k_{\text {on }}(1 / \mathrm{Ms})$ & $k_{\text {on }}$ Error & $k_{\text {off }}(1 / s)$ & $k_{\text {off }}$ Error \\
\hline 166.7 & 0.0186 & 1.18E-07 & 7.09E-06 & $4.06 \mathrm{E}+03$ & $1.40 \mathrm{E}+05$ & 4.77E-04 & 2.36E-02 \\
\hline 333.3 & 0.0619 & 6.92E-09 & 4.25E-09 & $6.74 \mathrm{E}+04$ & $2.77 E+04$ & 4.66E-04 & $2.13 E-04$ \\
\hline 666.7 & 0.1024 & 2.27E-09 & 6.36E-10 & $9.40 \mathrm{E}+04$ & $2.27 \mathrm{E}+04$ & $2.13 E-04$ & $3.05 \mathrm{E}-05$ \\
\hline 1333 & 0.153 & 8.56E-09 & 7.67E-10 & $4.60 E+04$ & $2.66 \mathrm{E}+03$ & 3.94E-04 & $2.69 \mathrm{E}-05$ \\
\hline 2667 & 0.199 & 8.77E-09 & 1.31E-09 & $4.64 \mathrm{E}+04$ & $6.63 E+03$ & 4.07E-04 & $1.84 \mathrm{E}$ \\
\hline Average & & & & $6.34 \mathrm{E}+04$ & & $3.70 \mathrm{E}-04$ & \\
\hline
\end{tabular}

Figure S1. Biolayer interferometry data to derive $k_{\text {on }}$ and $k_{\text {off }}$ values. For loading, biotinylated BSA $(10 \mu \mathrm{g} / \mathrm{mL}$ ) was immobilized on a streptavidin (SA) sensor for $120 \mathrm{~s}$ in Phosphatebuffered saline (PBS) $+0.002 \%$ Tween 20 . The association kinetics were evaluated using 25 400 $\mu \mathrm{g} / \mathrm{mL}$ anti-BSA IgG in PBS $+0.002 \%$ Tween 20 for $300 \mathrm{~s}$, while the dissociation rate was measured using PBS $+0.002 \%$ Tween 20 for $300 \mathrm{~s}$. The curves were fitted using Data Analysis $8.1 \mathrm{HD}$ software (Pall FortéBio) based on the bivalent (1:2) model. The association kinetics were evaluated using the data for $0 \sim 180 \mathrm{~s}$. 
(a)

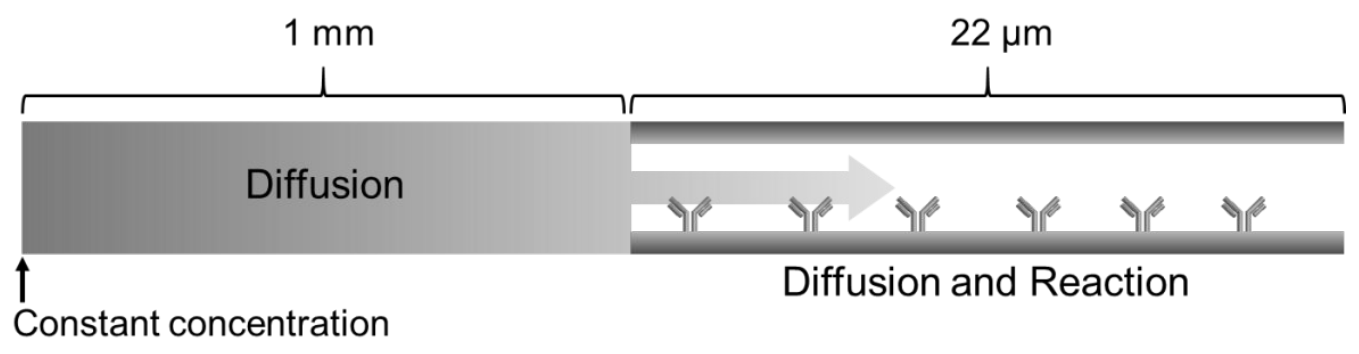

(b)

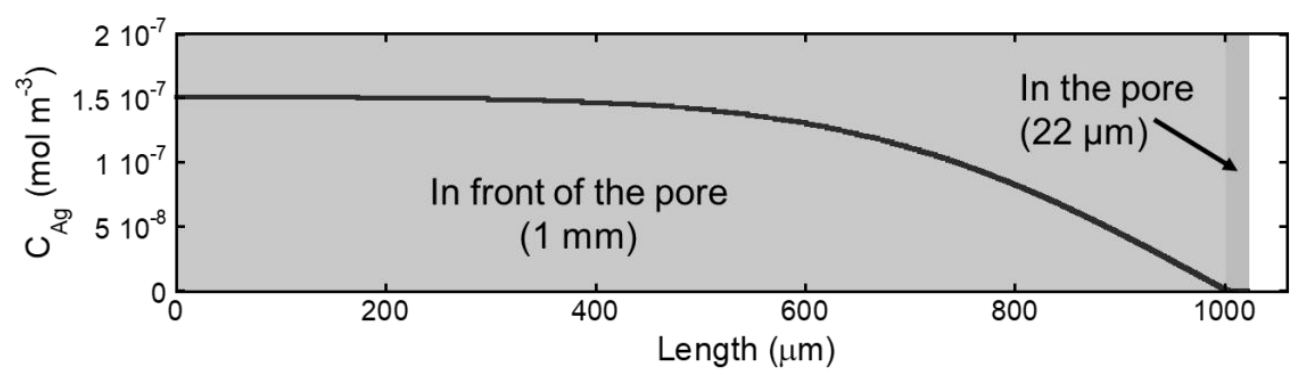

Figure S2. (a) Schematic image of the model without flow. In the model, the 1-mm region where only diffusion occurs is set in front of the pore. At the left end, the concentration is constant and is assumed to be same as the initial concentration. (b) Calculated result when a solution of $10 \mathrm{ng} / \mathrm{mL} \mathrm{Ag}\left(=1.5 \times 10^{-7} \mathrm{~mol} / \mathrm{m}^{3}\right)$ is used. The $X$ axis is the distance from the left end in (a); thus, $0-1000 \mu \mathrm{m}$ is the region where only diffusion occurs, and 1000-1022 $\mu \mathrm{m}$ is in the pore. The concentration dramatically decreased near the pore when the flow was not used. 


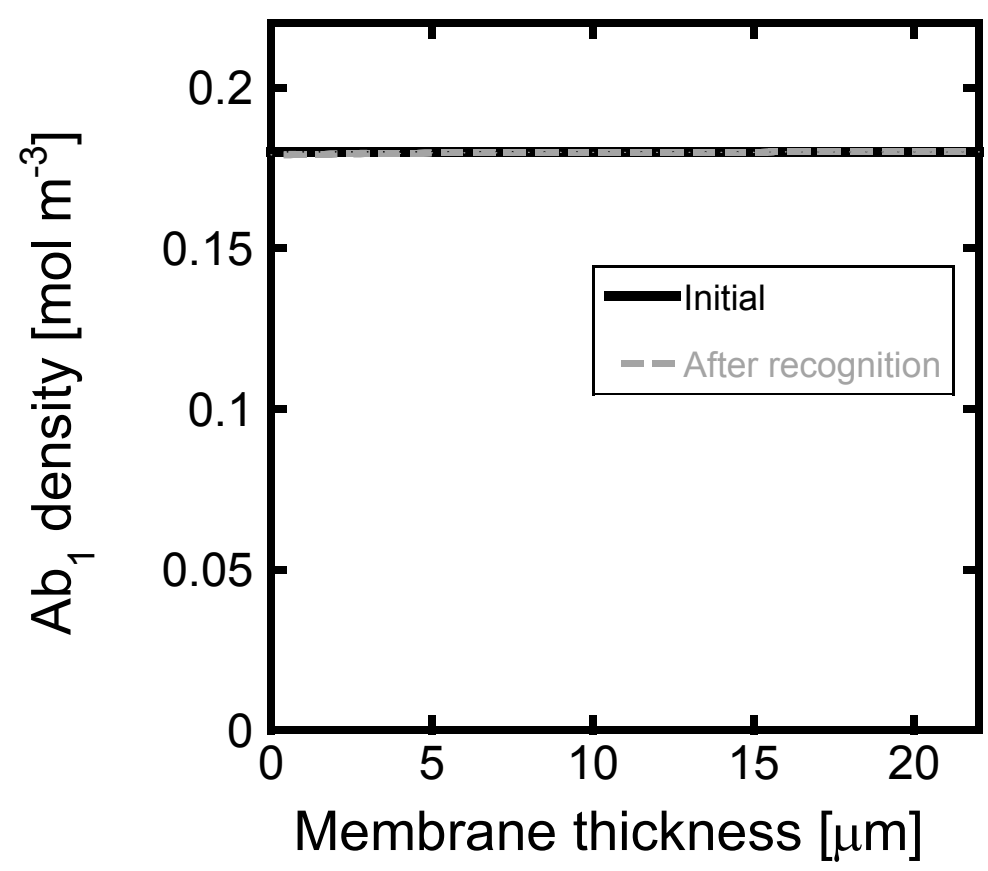

Figure S3. Calculated density of the $A b_{1}$ before and after recognition. The recognition condition is the same as in Figure 4(a). 


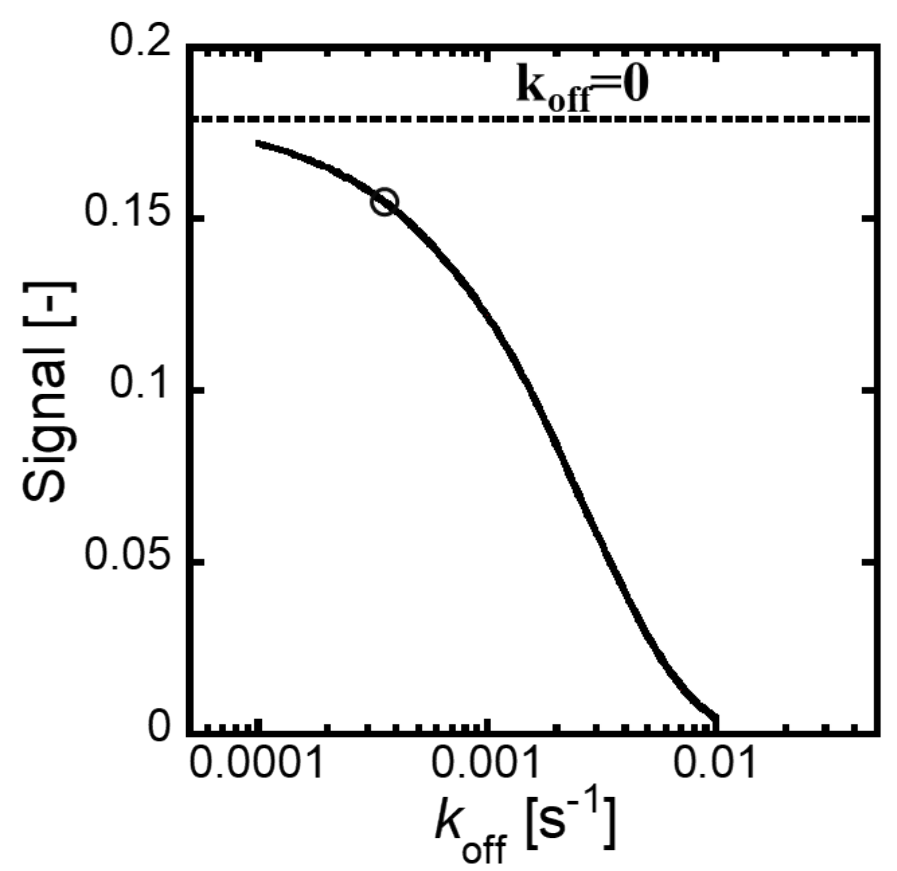

Figure S4. Calculated signal when the $\mathrm{k}_{\text {off }}$ value is different from that of the experimental condition. $\bigcirc$ is the experimental condition. The signal is not significantly improved by improving the $k_{\text {off }}$ value.

\section{References}

1. (1) Butler, J. E.; Ni, L.; Nessler, R.; Joshi, K. S.; Suter, M.; Rosenberg, B.; Chang, J.; Brown, W. R.; Cantarero, L. A. J. Immunol.I Methods 1992, 150, 77-90. 